\title{
Characteristics of metallic nanoparticles emitted from heated Kanthal e-cigarette coils
}

\author{
Mark D. Wilson • Kaushal A. Prasad • \\ Jong Sung Kim • Jae Hong Park $\mathbb{D}$
}

Received: 29 January 2019 /Accepted: 2 July 2019/Published online: 12 July 2019

(C) The Author(s) 2019

\begin{abstract}
Electronic (e-) cigarette use is becoming more common among youth and young adults. Ecigarette users may inhale metallic particles from the heating coil along with the nicotine vapor. This study aims to develop and validate an e-cigarette generation system for future inhalation toxicology studies of ecigarettes by characterizing the size and number of metallic nanoparticles produced and their chemical compositions. An e-cigarette generation system was constructed and Kanthal A1 coils were tested without a nicotine solution and wick under operating conditions of varying coil resistance $(0.1-1.0 \Omega)$, applied power $(10-70 \mathrm{~W})$, and duty cycle $(5-50 \%)$. The size distribution and morphology of particles were characterized using a scanning mobility particle sizer and a transmission electron microscopy, respectively. The size of generated particles, as well as the number of particles generated, exhibited an increasing trend as the resistance of
\end{abstract}

M. D. Wilson · K. A. Prasad · J. H. Park $(\bowtie)$

School of Health Sciences, Purdue University,

West Lafayette, IN 47907, USA

e-mail: park895@purdue.edu

M. D. Wilson

e-mail: wilso774@purdue.edu

K. A. Prasad

e-mail: prasad@purdue.edu

J. S. Kim

Department of Community Health and Epidemiology,

Dalhousie University, Halifax NS B3H 4R2, Canada

e-mail: jskim@Dal.Ca the coil increased. An initial large increase in size and number of particles generated was observed with increasing applied power, stabilizing with further increases in power. Increases in duty cycle resulted in increased particle generation. A similar pattern of particle generation was observed from the metal heating coils under various operating conditions. Under each operating condition, the number of generated particles exhibited a steep decrease during the first $15 \mathrm{~min}$ of each test run. Our results show this e-cigarette generation system is useful for future research investigating the health impact of metallic particle inhalation on e-cigarette users.

Keywords Metal coils · Electronic nicotine delivery systems (ENDS) · Metal oxides · Size distribution · Nanoscale aerosols $\cdot$ Health effects

\section{Introduction}

An electronic (e-) cigarette is an electronic device designed to allow users to inhale an aerosol typically containing nicotine, flavorings, and other additives. A primary reason for using e-cigarettes is for individuals who want to quit smoking or reduce the negative health impacts of cigarette smoking (Rutten et al. 2015; Goniewicz et al. 2013; Glasser et al. 2017). As reported in literature, e-cigarette use is increasing and gaining in popularity. Earlier data showed the use of e-cigarettes more than quadrupled, from 0.6 to $2.7 \%$ of the population from 2009 to 2010 (Regan et al. 2013), while later 
studies show a less of an increase in use. The reported use of e-cigarettes doubled from 2013 to 2014 in the USA (United States Public Health Service Office of the Surgeon General 2016), while doubling in the use of ecigarettes was observed over a 2-year period in Great Britain (Dockerell et al. 2013). In spite of large reported increases, the actual prevalence of e-cigarette use at this point is still relatively low, with reported use of around 3 to $5 \%$ of adults (Regan et al. 2013; Schoenborn 2015; Pearson et al. 2012; Sutfin et al. 2013). Young people, under 25 years of age, are more likely to use e-cigarettes, with reported use declining with advancing age (Vardavas et al. 2015; Sutfin et al. 2013).

The basic design of an e-cigarette is a battery, an atomizer, and chamber storing a nicotine solution (Knorst et al. 2014; Hon 2013). Some types of e-cigarettes may have flow sensor to detect changes in air pressure that occur when someone inhales from the e-cigarette (Brown and Cheng 2014). A heating element in the atomizer aerosolizes the liquid, which is then inhaled by the user (Brown and Cheng 2014; Drummond and Upson 2014). Since e-cigarettes do not produce the toxic combustion products found in regular tobacco cigarettes (Glasser et al. 2017), the risk of cancer caused by cigarette smoke could be reduced. Population surveys regarding the use of e-cigarettes have found the majority of people surveyed believe that e-cigarettes are less harmful than regular cigarettes (Pearson et al. 2012; Goniewicz, et al. 2013; Xu et al. 2016). The actual health effects associated with e-cigarette use need to be further explored in order to determine whether, in fact, this system is less harmful than traditional cigarettes.

Cigarette smoking has been associated with a number of adverse health outcomes. Traditional cigarettes contain various quantities of many different metals, including chromium $(\mathrm{Cr})$, nickel $(\mathrm{Ni})$, aluminum $(\mathrm{Al})$, cadmium $(\mathrm{Cd})$, copper $(\mathrm{Cu})$, lead $(\mathrm{Pb})$, and manganese $(\mathrm{Mn})$ (Bernhard et al. 2005). While many of the constituents of cigarette smoke are responsible for the observed health effects, inhalation of toxic metals is one of the mechanisms by which cigarette smoke exerts its toxic effects. Cancer is one of the more serious health outcomes linked with metal exposure from cigarette smoke. $\mathrm{Cr} \mathrm{VI}$ is designated by the International Agency for Research on Cancer (IARC) as a group I carcinogen and classified as a group A carcinogen by the EPA for inhalation (Wilbur et al. 2000). Ni has been associated with various types of cancer, targeting the respiratory tract in particular (Bernhard et al. 2005; Fay et al. 2005).
The metal content of cigarette smoke contributes to cardiovascular disease as well. Serum $\mathrm{Cu}$ levels have been shown to increase with cigarette smoking. This increase in serum $\mathrm{Cu}$ levels has been associated with a decrease in serum HDL cholesterol levels (Kromhout et al. 1985). The respiratory system also incurs damage as a result of metal inhalation. $\mathrm{Cu}$ is also an irritant to the respiratory system (Pettibone et al. 2008; Antonini et al. 2003). Ni has been associated with reduced lung function, chronic bronchitis, rhinitis, and asthma (Bernhard et al. 2005; Hess et al. 2017).

Metals have also found in the e-cigarette fumes. The process of particle generation is similar to one in glowing wire generator systems (Khan et al. 2014; Boskovic and Agranovski 2013; Peineke et al. 2006). Heating coils used in e-cigarette atomizers can produce metallic nanoparticles due to evaporation when electrical power is applied. Evaporated metals condense and coagulate into nanoparticle clusters, with individual particles attracted by Van der Waals forces (Boies et al. 2011; Schmidt-Ott and Burtscher 1982). The particles produced from the atomizer during the heating of the nicotine contain a variety of metals in different concentrations. Various metals have been reported in the aerosols generated by e-cigarettes (Olmedo et al. 2018; Saffari et al. 2014; Williams et al. 2017; Mikheev et al. 2016; Palazzolo et al. 2016). Iron (Fe), $\mathrm{Al}, \mathrm{Cu}, \mathrm{Cr}, \mathrm{Ni}$, and zinc $(\mathrm{Zn})$ are metals which have been previously found in relatively high concentration of e-cigarette fumes (Olmedo et al. 2018; Williams et al. 2017; Mikheev et al. 2016; Lerner et al. 2015). The concentration of each metal is dependent upon the type of coil used in the atomizer (Williams et al. 2017; Olmedo et al. 2018). Detailed aerosol generation data from specific coil materials are not available to date.

Coils made of Kanthal (Sandvik Group, Hallstahammar, Sweden) are widely used as a heating coil because of their high electrical resistance. Kanthal is a commercial name of metal alloy consisting primarily of Fe, Cr, and Al. Trace amounts of Mn, silicon (Si), and carbon (C) are present as well. Kanthal has been shown to produce higher concentrations of $\mathrm{Fe}, \mathrm{Cr}, \mathrm{Pb}$, and tin $(\mathrm{Sn})$, than other e-cigarette coil types (Olmedo et al. 2018). In this study, we tested the Kanthal e-cigarette coil without a nicotine solution in order to characterize the size distribution and chemical composition of the metallic nanoparticles generated from heating of a dry ecigarette coil. This allows for accurate determination of the particle size distribution of generated metallic 
particles, prior to contacting a nicotine solution and provides background data for future toxicology study of e-cigarette.

\section{Methods}

Experimental setup

As shown in Fig. 1, the experimental setup consisted of an air supply system, an e-cigarette generation system, and a measurement system. The air supply system was composed of an oil trap, a diffusion dryer, and a highefficiency particulate air (HEPA) filter to remove oil contaminants, humidity, and particles, respectively. The dry, particle-free air, controlled with a mass flow controller (MC-10SLPM-TFT, Alicat Scientific, Inc., USA), was delivered to a glass chamber at the flow rate of $5 \mathrm{~L} / \mathrm{min}$ to create sheath air surrounding atomizer. The e-cigarette generation system consisted of an atomizer, a controller, a diaphragm pump, and the glass chamber. Kanthal A1 coil (diameter of $0.405 \mathrm{~mm}$ (26 Ga.), inner diameter of $3 \mathrm{~mm}$ ) was installed in the atomizer. A box modified (MOD) type controller was used in the system. The diaphragm pump supplied the air from the atomizer to the sampling chamber $(9 \mathrm{~L}$, $0.18 \mathrm{~m} \times 0.18 \mathrm{~m} \times 0.28 \mathrm{~m}$ ) at the flow rate of $2.5 \mathrm{~L} / \mathrm{min}$.

The size distributions of the particles emitted from the atomizer were measured using a scanning mobility particle sizer (SMPS; 3938, TSI Inc., USA), consisting of a classifier controller (3082, TSI Inc., USA), a differential mobility analyzer (DMA; 3081A, TSI Inc. USA), a condensation particle counter (CPC; 3776, TSI Inc., USA), and a soft X-ray aerosol neutralizer (3088; TSI Inc., USA). The size distributions of emitted particles were measured every 1 min during a 30-min sampling run. Geometric mean diameter (GMD), geometric standard deviation (GSD), and total number concentration (TNC) were calculated using an aerosol instrument manager (Version 10.2.0.11, TSI Inc., USA).

In order to examine the morphology and chemical composition of the generated particles, a sample was collected onto a transmission electron microscope (TEM) grid (300-mesh, Au grid, Ultrathin Carbon Film on Lacey Carbon Support Film, 01824G, Ted Pella, Inc., USA) using an ESPnano (Model 100, DASH Connector Technology, Inc., USA). Morphology of collected particle was examined using a TEM (Talos 200X, ThermoFisher Scientific, USA). Elemental composition of particles was obtained using an energy dispersive Xray spectroscopy (Talos 200X, ThermoFisher Scientific, USA). The spectral peaks obtained were compared against standard peaks for the elements of interest.

Experimental procedure

Test settings were adjusted to mimic various operation conditions. In the first test condition, the atomizer was turned on and off at a consistent rate $(0.1 \mathrm{~Hz}$ frequency and $50 \%$ duty cycle), with $10 \mathrm{~W}$ of applied power, and tested with different coil resistance settings $(0.1,0.3$, 0.5 , and $1.0 \Omega$ ). The second test condition involved applying increasing amounts of power to the coil, starting with $10 \mathrm{~W}$ and increasing the power in

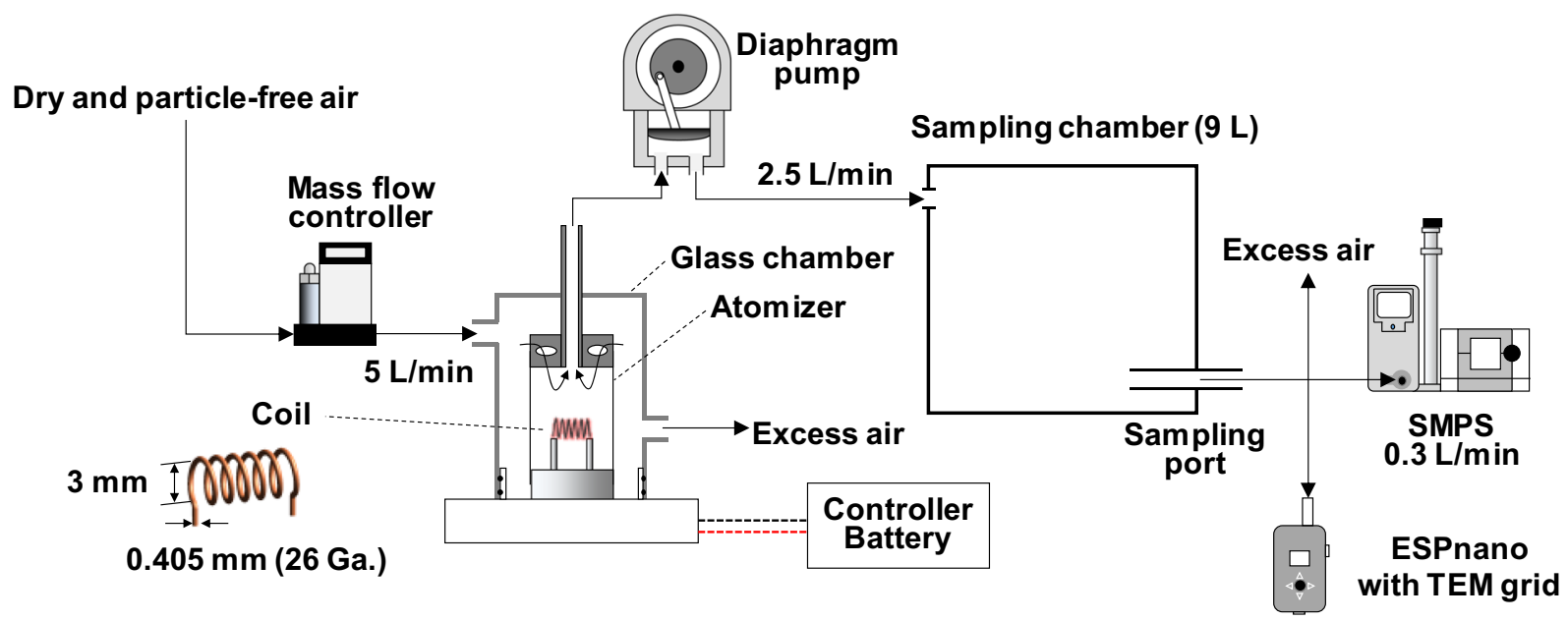

Fig. 1 Experimental setup 
increments of $20 \mathrm{~W}$, with a $5 \%$ duty cycle and a resistance of $0.5 \Omega$. The final test condition involved varying the duty cycle $(5 \%, 10 \%, 15 \%$, and $50 \%)$, with a consistent resistance of $0.5 \Omega$ and applied power of $10 \mathrm{~W}$. Each test condition ran for a period of $30 \mathrm{~min}$. Three trials were conducted for each test condition, with the average of the trials used in the data analysis. A new coil was tested for each trial.

Test Kanthal A1 coil material was analyzed using an inductively coupled plasma (ICP)-mass spectrometry (MS). Test coil was digested using a Discover SP-D Microwave Digester (CEM, NC, USA) and diluted 45 times to get a final $\mathrm{HNO}_{3}$ concentration of $2 \%(v / v)$. An ICAP-Q ICP-MS (Thermo Fisher Scientific, MA USA) paired with an ESI SC-4DXS Autosampler (Elemental Scientific, NE, USA) was used to measure 39 elements (Ag, Al, As, B, Ba, Be, Cd, Ce, Co, Cr, Cs, Cu, Dy, Er, $\mathrm{Eu}, \mathrm{Fe}, \mathrm{Ga}, \mathrm{Gd}, \mathrm{Hg}, \mathrm{Ho}, \mathrm{La}, \mathrm{Lu}, \mathrm{Mn}, \mathrm{Nd}, \mathrm{Ni}, \mathrm{Pb}, \mathrm{Pr}, \mathrm{Rb}$, Se, Sm, Sr, Th, Ti, Tl, Tm, U, V, Yb, and Zn). All samples were run in kinetic energy discrimination (KED) mode, using high purity helium (99.999\%) as the collision gas. Online internal standard addition was performed using $50 \mu \mathrm{g} / \mathrm{L}$ scandium and an SC FAST Valve (Elemental Scientific, NE, USA). The ICP-MS was run with a dwell time of $0.01 \mathrm{~s}$ for all analytes, with 25 sweeps and three main runs per sample.

\section{Results and discussion}

Particle size distributions according to various operating conditions

\section{Coil resistance}

The particle size distributions are documented in Fig. 2 and Table 1. Size distributions of generated particles were log-normally distributed with a GSD ranging from 1.2 to 1.6 , depending upon the coil resistance. As the resistance of the test coils increased, the GMD of the particles, produced due to condensation of vaporized metal from the Kanthal A1 coil, increased from $40 \mathrm{~nm}$, at $0.1 \Omega$, to $52 \mathrm{~nm}$, at $1.0 \Omega, 1 \mathrm{~min}$ into the sampling period (Fig. 2a). The GMD of the particles exhibited an approximate $10 \%$ increase in size as the coil resistance increased from 0.1 to $0.3 \Omega$. The GMD of generated particles then remained stable from 0.3 to $0.5 \Omega$. As the resistance of the coil increased from 0.5 to $1.0 \Omega$, the GMD increased approximated of $27 \%$. Stabilization of
GMD occurred approximately $10 \mathrm{~min}$ into the sampling period (Fig. 2c). The GMD was relatively stable throughout the sampling period at a resistance of $0.1 \Omega$. At higher resistances, the GMD increased 10 to $15 \mathrm{~min}$ into the sampling period before stabilizing.

The concentration of generated particles also varied by coil resistance. The average TNC generated over the sampling period increased over seven fold as the coil resistance was increased from 0.1 to $1.0 \Omega$. The magnitude of increase in TNC was not directly correlated with the level of increase in coil resistance (Fig. 2a). The TNC of particles showed an initial large increase of two and half fold from a $0.1 \Omega$ resistance to a $0.3 \Omega$ resistance setting. A more modest increase in TNC of 50\% occurred from an increase in coil resistance from 0.3 to $0.5 \Omega$. As the resistance was increased from 0.5 to $1.0 \Omega$, the resulting TNC nearly doubled. The TNC exhibited a rapid rate of decay over the sampling period, decreasing to half the concentration every $3.6 \mathrm{~min}$.

\section{Applied power}

Size distributions of generated particles were lognormally distributed with a GSD ranging from 1.2 up to 1.6 , reached at the end of the sampling period of the highest power setting (Fig. 3a and Table 1). The GMD of generated particles increased from 35 to $55 \mathrm{~nm}, 1 \mathrm{~min}$ into the sampling period, as the applied power was increased from 10 to $30 \mathrm{~W}$. This effect of a large increase in GMD with an increase of power did not hold for additional power settings. As the applied power was increased in $20 \mathrm{~W}$ increments, from 30 to $70 \mathrm{~W}$, the GMD decreased from 30 to $50 \mathrm{~W}$, and increased slightly from 50 to $70 \mathrm{~W}$. The GMD exhibited relative stability throughout the sampling period from 10 to $70 \mathrm{~W}$.

The concentration of generated particles showed an increase of over seven fold over the various power levels. An initial large increase of seven and a half fold in the TNC was observed from 10 to $30 \mathrm{~W}$ of applied power (Fig. 3d). The TNC remained stable with an increase in power to $50 \mathrm{~W}$, decreased slightly by $6 \%$ as power increased to $70 \mathrm{~W}$ of applied power. The TNC showed a rapid decay rate in which the concentration decreased by one-half every $3.6 \mathrm{~min}$. A study by Olmedo et al. (2018) investigated the effects of varying voltage applied to e-cigarette coils produced somewhat comparable results. Aerosol concentrations of Fe increased over 10 fold from the low voltage to intermediate voltage setting, but stabilized with a high voltage 
Fig. 2 Particle size distributions by resistance $\mathbf{a}$ at $1 \mathrm{~min}$ and $\mathbf{b}$ at 3 min. c Geometric mean diameters and $\mathbf{d}$ total number concentrations over sampling time (a)

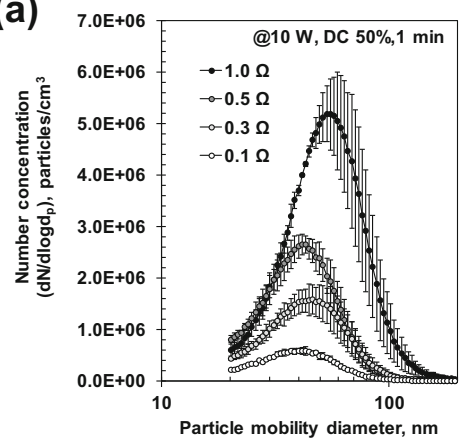

(c)

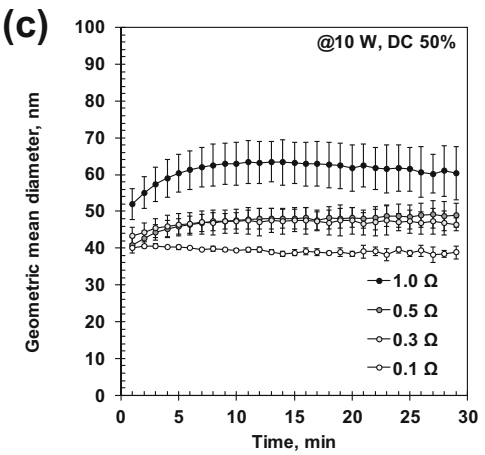

(b)

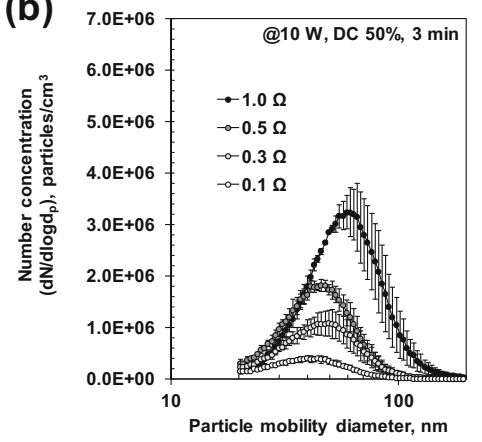

(d)

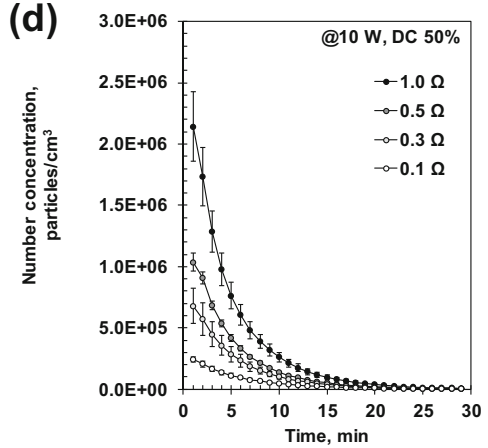

setting. Ni showed a similar trend, but less dramatic increase in concentration.

\section{Duty cycle}

A doubling of the duty cycle (5 to $10 \%$ ) resulted in an increase in the GMD of the particles from 35 to $38 \mathrm{~nm}$ $1 \mathrm{~min}$ into the sampling period (Fig. 4). The GMD exhibited a larger increase, from 38 to $46 \mathrm{~nm}$, as the duty cycle progressed from 10 to a $15 \%$ duty cycle. A further increase in the duty cycle time, from 15 to $50 \%$, resulted in a modest decline in the GMD from 46 to $41 \mathrm{~nm}$. The GMD was relatively stable throughout the sampling period with the $5 \%$ duty cycle. The GMD for the $10 \%$ and $15 \%$ duty cycle initially increased through the first $20 \mathrm{~min}$ of the sampling period, after which the GMD began to showing a decreasing trend.

The GMD showed a progressive increase throughout the sampling period for the $50 \%$ duty cycle (Fig. 4c). The TNC of particles increased eight and half fold as the duty cycle was increased from 5 to $10 \%$ (Fig. 4d). A further increase in duty cycle from 10 to $15 \%$ resulted in a more modest $14 \%$ increase in the TNC. The TNC remained stable as the duty cycle was increased from 15 to $50 \%$, exhibiting a small $4 \%$ increase. A rapid rate of decline in TNC was noted over the sampling period, with the concentration decreasing by one-half each $3.5 \mathrm{~min}$.

Composition analysis, TEM images, and EDX maps

The first image in Fig. 5 illustrates the shape of the particle generated from a resistance of $0.5 \Omega$ at the applied power of $10 \mathrm{~W}$. The collected particle appears as aggregated formed from much smaller primary particles. However, it was difficult to identify individual primary particles since they were coagulated and then might be sintered (partially melted) by heat from coil.

The TEM image of the particle is combined with EDX maps. These maps correspond to $\mathrm{Fe}, \mathrm{O}, \mathrm{Al}, \mathrm{Si}$, $\mathrm{Mn}$, and $\mathrm{Cr}$, respectively. The dots in these images indicate the positions of each element in the first image. For example, $\mathrm{Fe}$ and $\mathrm{O}$ are concentrated in the regions corresponding to the particles in the first image, which shows that the particles contain $\mathrm{Fe}$ and O. The composition of the collected particle was dominated by Fe and $\mathrm{O}$ as documented in the Table 2. The fractions of Fe and $\mathrm{O}$ were 0.56 and 0.40 in mass, respectively. Fe oxide is an expected finding, as filtered air rather than an inert gas was used as the carrier gas, in which case metallic particles would have been generated (Khan et al. 2014). Analysis of the coil material revealed that the Kanthal 
Table 1 Particle size distribution and total number concentration under various operating conditions

\begin{tabular}{|c|c|c|c|c|c|c|c|c|}
\hline \multirow[b]{3}{*}{$\begin{array}{l}\text { Time } \\
\qquad(\min )\end{array}$} & \multicolumn{8}{|c|}{ Resistance of coil $(\Omega)$} \\
\hline & \multicolumn{2}{|l|}{0.1} & \multicolumn{2}{|l|}{0.3} & \multicolumn{2}{|l|}{0.5} & \multicolumn{2}{|l|}{1.0} \\
\hline & $\begin{array}{l}\text { GMD } \\
(\mathrm{nm})\end{array}$ & $\begin{array}{l}\text { TNC } \\
\quad\left(\text { particles } / \mathrm{cm}^{3}\right)\end{array}$ & $\begin{array}{l}\text { GMD } \\
\quad(\mathrm{nm})\end{array}$ & $\begin{array}{l}\mathrm{TNC} \\
\quad\left(\text { particles } / \mathrm{cm}^{3}\right)\end{array}$ & $\begin{array}{l}\text { GMD } \\
(\mathrm{nm})\end{array}$ & $\begin{array}{l}\text { TNC } \\
\quad\left(\text { particles } / \mathrm{cm}^{3}\right)\end{array}$ & $\begin{array}{l}\text { GMD } \\
\quad(\mathrm{nm})\end{array}$ & $\begin{array}{l}\mathrm{TNC} \\
\quad\left(\text { particles } / \mathrm{cm}^{3}\right)\end{array}$ \\
\hline 1 & $40 \pm 0$ & 243,774 & $43 \pm 2$ & 678,923 & $41 \pm 2$ & $1,037,011$ & $52 \pm 4$ & $2,142,568$ \\
\hline 3 & $41 \pm 1$ & 165,616 & $45 \pm 3$ & 448,847 & $44 \pm 2$ & 685,374 & $57 \pm 5$ & $1,286,833$ \\
\hline 5 & $40 \pm 1$ & 112,711 & $46 \pm 3$ & 284,414 & $46 \pm 2$ & 417,286 & $60 \pm 5$ & 764,094 \\
\hline 10 & $39 \pm 0$ & 45,171 & $47 \pm 3$ & 102,008 & $48 \pm 2$ & 139,232 & $63 \pm 6$ & 262,634 \\
\hline 15 & $39 \pm 1$ & 19,715 & $48 \pm 3$ & 38,842 & $48 \pm 3$ & 51,670 & $63 \pm 6$ & 98,584 \\
\hline 20 & $38 \pm 1$ & 23,943 & $47 \pm 4$ & 14,987 & $48 \pm 3$ & 19,705 & $62 \pm 6$ & 37,877 \\
\hline 25 & $39 \pm 1$ & 3992 & $47 \pm 3$ & 5482 & $48 \pm 3$ & 8079 & $61 \pm 6$ & 14,969 \\
\hline \multirow[t]{3}{*}{29} & $39 \pm 2$ & 2087 & $46 \pm 2$ & 2668 & $49 \pm 3$ & 3717 & $60 \pm 7$ & 7359 \\
\hline & \multicolumn{8}{|c|}{ Applied power (W) } \\
\hline & \multicolumn{2}{|l|}{10} & \multicolumn{2}{|l|}{30} & \multicolumn{2}{|l|}{50} & \multicolumn{2}{|l|}{70} \\
\hline $\begin{array}{l}\text { Time } \\
\qquad(\min )\end{array}$ & $\begin{array}{l}\text { GMD } \\
(\mathrm{nm})\end{array}$ & $\begin{array}{l}\text { TNC } \\
\quad\left(\text { particles } / \mathrm{cm}^{3}\right)\end{array}$ & $\begin{array}{l}\text { GMD } \\
\quad(\mathrm{nm})\end{array}$ & $\begin{array}{l}\text { TNC } \\
\quad\left(\text { particles } / \mathrm{cm}^{3}\right)\end{array}$ & $\begin{array}{l}\text { GMD } \\
(\mathrm{nm})\end{array}$ & $\begin{array}{l}\text { TNC } \\
\quad\left(\text { particles } / \mathrm{cm}^{3}\right)\end{array}$ & $\begin{array}{l}\text { GMD } \\
\quad(\mathrm{nm})\end{array}$ & $\begin{array}{l}\mathrm{TNC} \\
\quad\left(\text { particles } / \mathrm{cm}^{3}\right)\end{array}$ \\
\hline 1 & $35 \pm 1$ & 99,763 & $55 \pm 4$ & 754,865 & $49 \pm 1$ & 777,530 & $52 \pm 2$ & 704,410 \\
\hline 3 & $34 \pm 1$ & 67,519 & $56 \pm 4$ & 483,721 & $51 \pm 1$ & 473,681 & $55 \pm 2$ & 448,230 \\
\hline 5 & $34 \pm 1$ & 42,621 & $57 \pm 3$ & 308,022 & $52 \pm 1$ & 298,642 & $56 \pm 2$ & 287,049 \\
\hline 10 & $33 \pm 1$ & 14,878 & $58 \pm 3$ & 111,477 & $54 \pm 1$ & 105,173 & $57 \pm 2$ & 103,472 \\
\hline 15 & $32 \pm 2$ & 5339 & $58 \pm 3$ & 42,160 & $53 \pm 2$ & 40,152 & $57 \pm 3$ & 40,892 \\
\hline 20 & $34 \pm 2$ & 1716 & $56 \pm 3$ & 16,412 & $51 \pm 2$ & 14,971 & $56 \pm 3$ & 16,135 \\
\hline 25 & $34 \pm 2$ & 660 & $55 \pm 4$ & 6223 & $50 \pm 3$ & 6102 & $55 \pm 3$ & 6698 \\
\hline \multirow[t]{3}{*}{29} & $36 \pm 5$ & 305 & $54 \pm 4$ & 3121 & $50 \pm 2$ & 2723 & $57 \pm 2$ & 3254 \\
\hline & \multicolumn{8}{|c|}{ Duty cycle $(\%)$} \\
\hline & \multicolumn{2}{|c|}{5 ( $0.5 \mathrm{~s}$ on, $9.5 \mathrm{~s}$ off $)$} & \multicolumn{2}{|c|}{$10(1 \mathrm{~s}$ on, $9 \mathrm{~s}$ off $)$} & \multicolumn{2}{|c|}{15 (1.5 s on, $8.5 \mathrm{~s}$ off $)$} & \multicolumn{2}{|c|}{$50(5 \mathrm{~s}$ on, $5 \mathrm{~s}$ off $)$} \\
\hline $\begin{array}{l}\text { Time } \\
\qquad(\min )\end{array}$ & $\begin{array}{l}\text { GMD } \\
(\mathrm{nm})\end{array}$ & $\begin{array}{l}\text { TNC } \\
\quad\left(\text { particles } / \mathrm{cm}^{3}\right)\end{array}$ & $\begin{array}{l}\text { GMD } \\
\quad(\mathrm{nm})\end{array}$ & $\begin{array}{l}\text { TNC } \\
\quad\left(\text { particles } / \mathrm{cm}^{3}\right)\end{array}$ & $\begin{array}{l}\text { GMD } \\
(\mathrm{nm})\end{array}$ & $\begin{array}{l}\text { TNC } \\
\quad\left(\text { particles } / \mathrm{cm}^{3}\right)\end{array}$ & $\begin{array}{l}\text { GMD } \\
\quad(\mathrm{nm})\end{array}$ & $\begin{array}{l}\text { TNC } \\
\quad\left(\text { particles } / \mathrm{cm}^{3}\right)\end{array}$ \\
\hline 1 & $35 \pm 1$ & 99,763 & $38 \pm 1$ & 856,575 & $46 \pm 2$ & $1,048,048$ & $41 \pm 2$ & $1,037,011$ \\
\hline 3 & $34 \pm 1$ & 67,519 & $40 \pm 1$ & 602,308 & $49 \pm 1$ & 633,138 & $44 \pm 2$ & 685,374 \\
\hline 5 & $34 \pm 1$ & 42,621 & $42 \pm 1$ & 357,146 & $50 \pm 2$ & 384,455 & $46 \pm 2$ & 417,286 \\
\hline 10 & $33 \pm 1$ & 14,878 & $44 \pm 1$ & 112,787 & $51 \pm 1$ & 130,844 & $48 \pm 2$ & 139,232 \\
\hline 15 & $32 \pm 2$ & 5339 & $43 \pm 2$ & 39,077 & $51 \pm 2$ & 46,779 & $48 \pm 3$ & 51,670 \\
\hline 20 & $34 \pm 2$ & 1716 & $41 \pm 1$ & 13,907 & $50 \pm 3$ & 18,447 & $48 \pm 3$ & 19,705 \\
\hline 25 & $34 \pm 2$ & 660 & $40 \pm 2$ & 4997 & $47 \pm 3$ & 6983 & $48 \pm 3$ & 8079 \\
\hline 29 & $36 \pm 5$ & 305 & $38 \pm 2$ & 2243 & $46 \pm 3$ & 3039 & $49 \pm 3$ & 4417 \\
\hline
\end{tabular}

wire is primarily comprised of $\mathrm{Fe}$ and $\mathrm{Al}$, along with lesser amount of $\mathrm{Cr}$ and $\mathrm{Mn}$ (Table 2). However, the $\mathrm{Al}$ content of generated particles was much less than the content of the Kanthal coil.

Discussion and limitations

Metallic nanoparticles were generated from e-cigarette coils in the range of 32 to $57 \mathrm{~nm}$, depending upon the test operating conditions. Large increases in TNC were also noted with increases resistance, applied power, and duty cycle. The pattern on TNC increase, however, differed by operating conditions. Coil resistance exhibited consistent increases in TNC with increasing wire resistance, while applied power showed an initial large increase in TNC, followed by a stabilization of concentration with further increases in power. Duty cycle showed a pattern intermediate of resistance and power, 
Fig. 3 Particle size distributions by applied power $\mathbf{a}$ at $1 \mathrm{~min}$ and $\mathbf{b}$ at 3 min. c Geometric mean diameters and $\mathbf{d}$ total number concentrations over sampling time
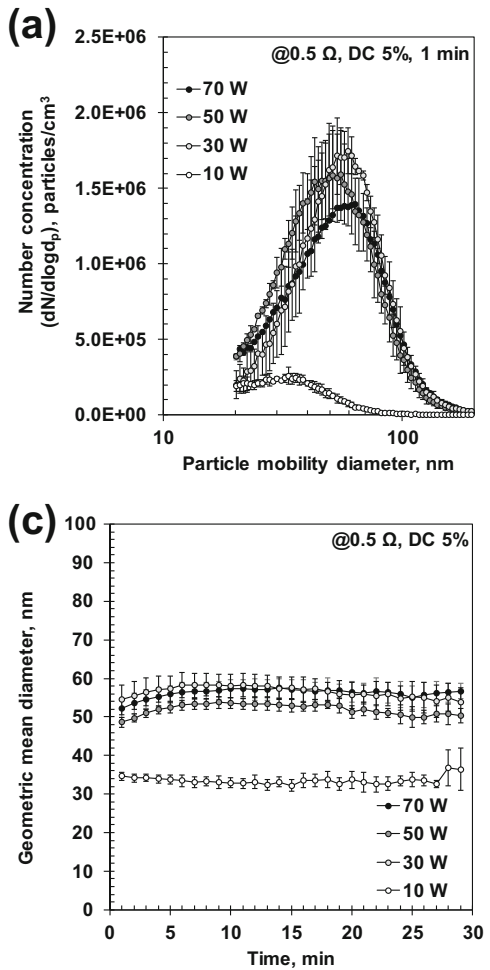
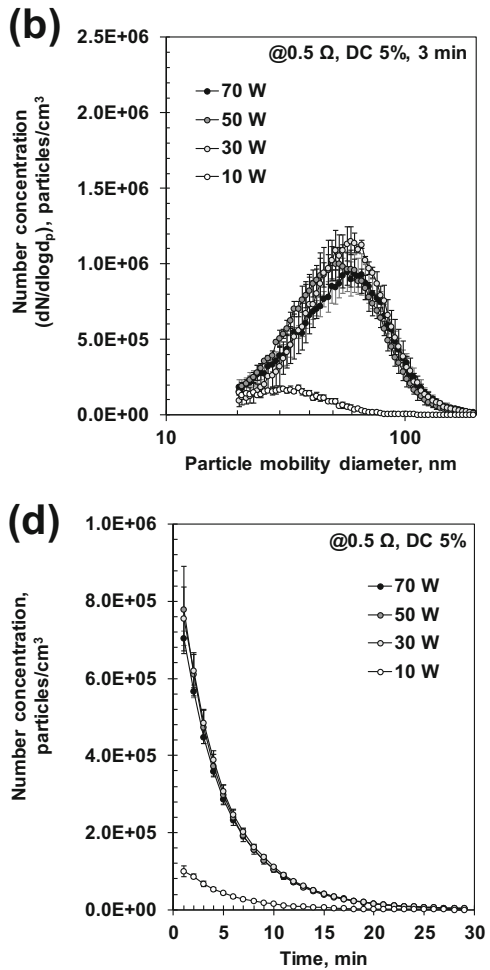

with increases of TNC with the first two changes in duty cycle length, followed by a stabilization.

Fig. 4 Particle size distributions by duty cycle $\mathbf{a}$ at $1 \mathrm{~min}$ and $\mathbf{b}$ at 3 min. c Geometric mean diameters and $\mathbf{d}$ total number concentrations over sampling time
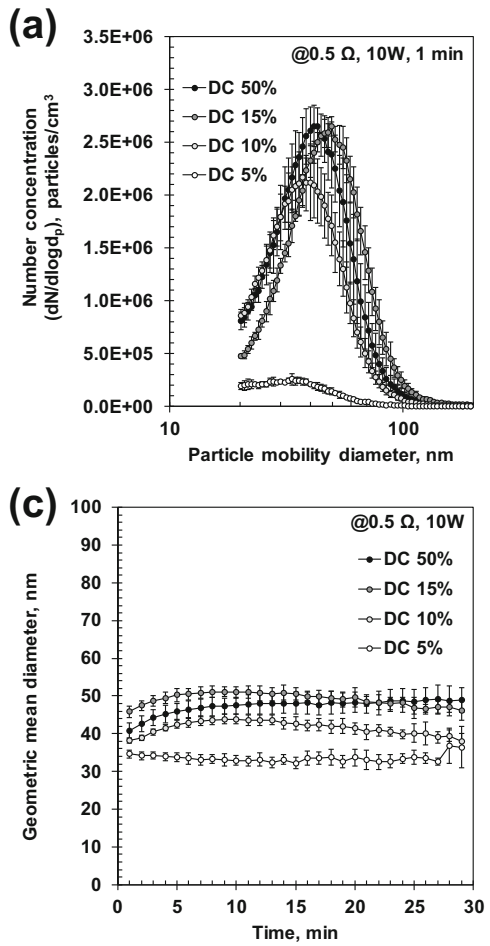
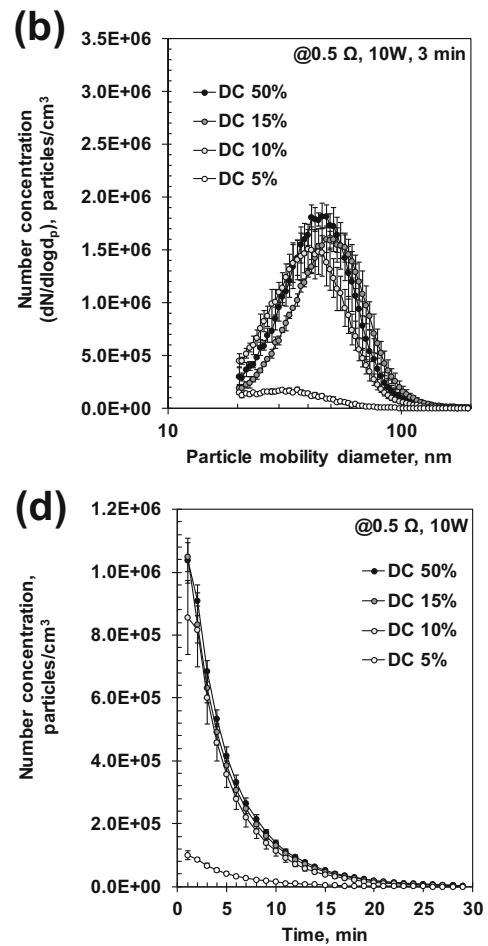

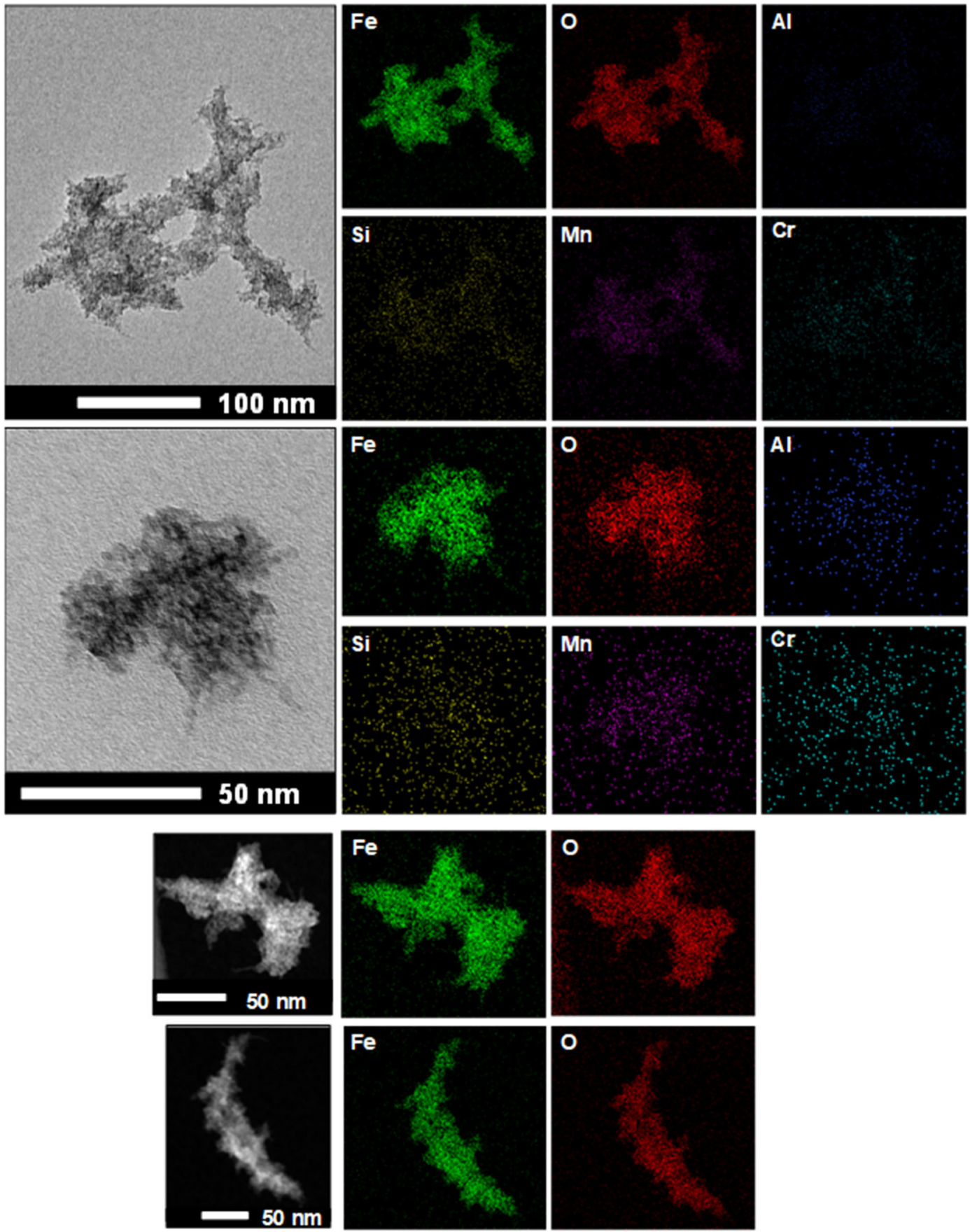

Fig. 5 TEM and EDX map images of sampled particles (these maps are for $\mathrm{Fe}, \mathrm{O}, \mathrm{Al}, \mathrm{Si}, \mathrm{Mn}$, and $\mathrm{Cr}$ )

aerosols from the e-cigarettes. These nanoparticles are able to penetrate into the interstitial space and elicit an inflammatory response (Oberdörster et al. 1994; Srinivas et al. 2012). Nanoparticles also translocate from the lungs to the lymphatic system, where they accumulate in the tracheobronchial lymph nodes (Srinivas et al.
2012; Takenaka et al. 1986), and the circulatory system (Takenaka et al. 1986; Miller et al. 2013), where they accumulate at the site of atherosclerotic plaque build-up (Miller et al. 2013). However, it is difficult to conclude that nanoparticles produced from e-cigarette coils can cause severe toxic effects because of limited 
Table 2 Metal contents in Kanthal wire and sampled particle

\begin{tabular}{llll}
\hline Test sample & Kanthal A1 wire & Sampled particles \\
\cline { 2 - 3 } Analysis method & ICP-MS & EDX* & Mass fraction $(\%)$ \\
\cline { 2 - 3 } Element & Element concentration $(\mu \mathrm{g} / \mathrm{g})$ & Atomic fraction $(\%)$ & $40.32 \pm 4.40$ \\
\hline $\mathrm{O}$ & N.A. & $66.97 \pm 3.92$ & $56.06 \pm 5.34$ \\
$\mathrm{Fe}$ & 30986.0 & $30.30 \pm 4.83$ & $0.20 \pm 0.05$ \\
$\mathrm{Al}$ & 2123.0 & $0.22 \pm 0.07$ & $2.08 \pm 1.06$ \\
$\mathrm{Si}$ & N.A. & $2.08 \pm 1.02$ & $0.11 \pm 0.04$ \\
$\mathrm{Cr}$ & 7877.5 & $0.06 \pm 0.02$ & $0.33 \pm 0.20$ \\
$\mathrm{Mn}$ & 63.6 & $0.18 \pm 0.12$ & $0.70 \pm 0.31$ \\
$\mathrm{~Pb}$ & 0.2 & $0.11 \pm 0.05$ & 0 \\
\hline
\end{tabular}

*Average values and standard deviations were calculated from EDX results of five particles

information. To consider the potential toxicity of metallic nanoparticles in humans, more detailed information such as mass based dose, chemical form, solubility, and surface area of particles should be analyzed. After characterization of nanoparticles, further research is needed to assess the effects of inhaled nanoparticles from ecigarettes on the respiratory and cardiovascular systems of e-cigarette users and others who may be exposed to ecigarette emissions.

We developed and validated our e-cigarette generation system by characterizing the size and number of nanoparticles produced and their chemical compositions. One finding of interest was the steep decrease in the TNC over the course of the sampling period. This effect was consistent across the various operating conditions (power, resistance, and duty cycle). A possible explanation for this observation may be the formation of a metal oxide layer on the surface of the heating coil (Boggs 1971; Prescott and Graham 1992; Sauer et al. 1982; Sundberg et al. 2004). When Al alloys undergo oxidation, they develop layers of protective alumina on the surface (Sundberg et al. 2004; Boggs 1971). Any breach in this layer allows for oxygen to contact the metal underneath that layer, resulting in the formation of Fe oxide (Boggs 1971). As this layer is formed, further metal evaporation, and particle generation, would be decreased. Utilization of an inert carrier gas, such as argon, would prevent the phenomenon from occurring, resulting in a stable production of particles over an extended period of time (Peineke et al. 2006). The rate at which oxidation occurs is dependent upon several factors. The amount of $\mathrm{Al}$ in the alloy is one of these factors. The oxidation rate of the material increases with a greater percentage of $\mathrm{Al}$ present, up to a certain amount, after which increasing $\mathrm{Al}$ content results in decreasing oxidation rate, as the alloy contains enough Al to resist Fe nodule formation (Boggs 1971; Prescott and Graham 1992). Exposure to high temperature (over $1,000{ }^{\circ} \mathrm{C}$ ) will result in an increased rate of oxidation (Sauer et al. 1982; Boggs 1971; Prescott and Graham 1992). Oxidation also proceeds more rapidly with water vapor present in the atmosphere (Boggs 1971). In order to reduce exposure to metallic nanoparticles from an ecigarette system, we recommend utilizing used or ceramic-coated metal coil, which will generate fewer particles than a new coil.

The results of this study need to be viewed in the presence of several limitations. Particles were generated using a modified e-cigarette system, under controlled conditions. The air supplied to the system was filtered and dehumidified. Since humidity affects the oxidation rate of the metal, e-cigarette use under normal operating conditions may exhibit a different particle generation rate. Additionally, the duty cycle set for the e-cigarette system in this study may not correspond with actual ecigarette usage patterns. Only one type of coil was used in this study. Future studies should investigate the particle generation characteristics of other materials used in e-cigarette coils.

The e-cigarette test was also conducted without the nicotine solution and the wick used in an e-cigarette system. The metallic nanoparticles generated from the coil may act as a seed for the growth of fumes from ecigarette solution and result in differences in the diameter of particles. The possibility also exists for particles to be generated from sources other than the e-cigarette 
coils. Additional sources of particles, generated from heating of the circuitry and housing material of the ecigarette system, may also contribute to the concentration of particles measured.

During the experiments, particles were generated intermittently based on duty cycle time, rather than a continuous process. For sampling steady-state particles, a sampling chamber was connected to the atomizer chamber (Fig. 1). The size of the nanoparticles generated may be increased due to coagulation occurring in the sampling chamber. Smaller particles would be expected if sampling occurred closer to the source of generation (Khan et al. 2014).

The test conditions of the e-cigarette generating system may not be representative of actual use patterns of an e-cigarette. The duration of a puff from an e-cigarette may vary by use, with inexperienced users taking shorter puff on the order of $2 \mathrm{~s}$ and experienced users taking longer puff of an average $4 \mathrm{~s}$ (Talih et al. 2015). Generally, the metal coil is surrounded by a wick and immersed in a nicotine solution. Exposure of the metal coil to the atmosphere, however, may occur once the reservoir containing the nicotine solution runs dry.

\section{Conclusions}

We developed an e-cigarette generation system to support future inhalation toxicology studies and tested the Kanthal e-cigarette coil without a nicotine solution by characterizing the size distribution and chemical composition of the metallic nanoparticles generated from heating of an e-cigarette coil. Under various test conditions, a similar pattern of aerosol generation was noted. GMD was ranged from 30 to $60 \mathrm{~nm}$. TNC was highest at the beginning of sampling and decreased over time due to surface oxidation of Kanthal coil. Fe and $\mathrm{O}$ contents were mainly found in particles generated from the coil. $\mathrm{Al}$ in Kanthal coil was not changed into nanoparticles. These results indicate that used or ceramic-coated metal coil could generate fewer particles than a new coil. The results are useful for future development of safer ecigarettes. Increasing the resistance of the e-cigarette coil, by varying the number of loops in the coil, increases the number of particles generate and results in increased exposure of metal nanoparticles to the user. The use of low resistance coils, along with applied power of less than $30 \mathrm{~W}$, is recommended to help minimize metal exposure. Future studies will focus on the particle emission from various coil materials and inhalation study of e-cigarette using this system.

Funding information Open access publication of this article was funded in part by School of Health Sciences, Purdue University.

\section{Compliance with ethical standards}

Conflict of interest The authors declare that they have no conflict of interest.

Open Access This article is distributed under the terms of the Creative Commons Attribution 4.0 International License (http:// creativecommons.org/licenses/by/4.0/), which permits unrestricted use, distribution, and reproduction in any medium, provided you give appropriate credit to the original author(s) and the source, provide a link to the Creative Commons license, and indicate if changes were made.

\section{References}

Antonini JM, Lewis AB, Roberts JR, Whaley DA (2003) Pulmonary effects of welding fumes: review of worker and experimental animal studies. Am J Ind Med 43(4):350-360

Bernhard D, Rossmann A, Wick G (2005) Metals in cigarette smoke. IUBMB Life 57(12):805-809

Boggs WE (1971) The oxidation of iron-aluminum alloys from $450^{\circ}$ to $900^{\circ} \mathrm{C}$. J Electrochem Soc 118(6):906-913

Boies AM, Lei P, Calder S, Shin WG, Girshick SL (2011) Hotwire synthesis of gold nanoparticles. Aerosol Sci Technol 45(5):654-663

Boskovic L, Agranovski IE (2013) An influence of a gas velocity on morphology of molybdenum oxide nanoparticles generated by a glowing wire generator. J Aerosol Sci 63:69-74

Brown CJ, Cheng JM (2014) Electronic cigarettes: product characterisation and design considerations. Tob Control 23(Suppl 2):ii4-ii10

Dockrell M, Morrison R, Bauld L, McNeill A (2013) E-cigarettes: prevalence and attitudes in Great Britain. Nicotine Tobacco Res 15(10):1737-1744

Drummond MB, Upson D (2014) Electronic cigarettes. Potential harms and benefits. Ann Am Thorac Soc 11(2):236-242

Fay M, Syracuse RC, States U (2005) Toxicological profile for nickel. Agency for Toxic Substances and Disease Registry, Atlanta

Glasser AM, Collins L, Pearson JL, Abudayyeh H, Niaura RS, Abrams DB, Villanti AC (2017) Overview of electronic nicotine delivery systems: a systematic review. Am J Prev Med 52(2):e33-e66

Goniewicz ML, Lingas EO, Hajek P (2013) Patterns of electronic cigarette use and user beliefs about their safety and benefits: an internet survey. Drug Alcohol Rev 32(2):133-140 
Hess CA, Olmedo P, Navas-Acien A, Goessler W, Cohen JE, Rule AM (2017) E-cigarettes as a source of toxic and potentially carcinogenic metals. Environ Res 152:221-225

Hon L (2013) Electronic cigarette. U.S. 8,511,318 B2.: United States Patent and Trademark Office; 20 August 2013

Khan A, Modak P, Joshi M, Khandare P, Koli A, Gupta A, Anand S, Sapra BK (2014) Generation of high-concentration nanoparticles using glowing wire technique. J Nanopart Res 16:2776

Knorst MM, Benedetto IG, Hoffmeister MC, Gazzana MB (2014) The electronic cigarette: the new cigarette of the 21 st century? J Bras Pneumol 40(5):564-572

Kromhout D, Wibowo A, Herber R, Dalderup L, Heerdink H, Zielhuis R (1985) Trace metals and coronary heart disease risk indicators in 152 elderly men (the Zutphen study). Am J Epidemiol 122(3):378-385

Lerner CA, Sundar IK, Watson RM, Elder A, Jones R, Done D, Kurtzman R, Ossip DJ, Robinson R, McIntosh S, Rahman I (2015) Environmental health hazards of e-cigarettes and their components: oxidants and copper in e-cigarette aerosols. Environ Pollut 198:100-107

Mikheev VB, Brinkman MC, Granville CA, Gordon SM, Clark PI (2016) Real-time measurement of electronic cigarette aerosol size distribution and metals content analysis. Nicotine Tobacco Res 18(9):1895-1902

Miller MR, McLean SG, Duffin R, Lawal AO, Araujo JA, Shaw CA et al (2013) Diesel exhaust particulate increases the size and complexity of lesions in atherosclerotic mice. Part Fibre Toxicol 10(1):61

Oberdörster G, Ferin J, Lehnert BE (1994) Correlation between particle size, in vivo particle persistence, and lung injury. Environ Health Perspect 102:173-179

Olmedo P, Goessler W, Tanda S, Grau-Perez M, Jarmul S, Aherrera A, Chen R, Hilpert M, Cohen JE, Navas-Acien A, Rule AM (2018) Metal concentrations in e-cigarette liquid and aerosol samples: the contribution of metallic coils. Environ Health Perspect 126(2):027010

Palazzolo DL, Crow AP, Nelson JM, Johnson RA (2016) Trace metals derived from electronic cigarette (ECIG) generated aerosol: potential problem of ECIG devices that contain nickel. Front Physiol 7:663

Pearson JL, Richardson A, Niaura RS, Vallone DM, Abrams DB (2012) E-cigarette awareness, use, and harm perceptions in US adults. Am J Public Health 102(9):1758-1766

Peineke C, Attoui MB, Schmitt-Ott A (2006) Using a glowing wire generator for production of charged, uniformly sized nanoparticles at high concentration. J Aerosol Sci 37:16511661

Pettibone JM, Adamcakova-Dodd A, Thorne PS, O'Shaughnessy PT, Weydert JA, Grassian VH (2008) Inflammatory response of mice following inhalation exposure to iron and copper nanoparticles. Nanotoxicology 2(4):189-204

Prescott R, Graham MJ (1992) The formation of aluminum oxide scales on high-temperature alloys. Oxid Met 38(3):233-254

Regan AK, Promoff G, Dube SR, Arrazola R (2013) Electronic nicotine delivery systems: adult use and awareness of the 'Ecigarette' in the USA. Tob Control 22(1):19-23

Rutten LJF, Blake KD, Agunwamba AA, Grana RA, Wilson PM, Ebbert JO, Okamoto J, Leischow SJ (2015) Use of ecigarettes among current smokers: associations among reasons for use, quit intentions, and current tobacco use. Nicotine Tobacco Res 17(10):1228-1234
Saffari A, Daher N, Ruprecht A, De Marco C, Pozzi P, Boffi R et al (2014) Particulate metals and organic compounds from electronic and tobacco-containing cigarettes: comparison of emission rates and secondhand exposure. Environ Sci Process Impact 16(10):2259-2267

Sauer J, Rapp R, Hirth J (1982) Oxidation of iron-manganesealuminum alloys at 850 and $1000^{\circ} \mathrm{C}$. Oxid Met 18(5):285294

Schmidt-Ott A, Burtscher H (1982) The effect of van der waals forces on aerosol coagulation. J Colloid Interface Sci 89(2): 353-357

Schoenborn CA (2015) Electronic cigarette use among adults: United States, 2014. U.S. Department of Health and Human Services, Centers for Disease Control and Prevention, National Center for Health Statistics, Atlanta

Srinivas A, Rao PJ, Selvam G, Goparaju A, Murthy BP, Reddy NP (2012) Oxidative stress and inflammatory responses of rat following acute inhalation exposure to iron oxide nanoparticles. Hum Exp Toxicol 31(11):1113-1131

Sundberg M, Malmqvist G, Magnusson A, El-Raghy T (2004) Alumina forming high temperature silicides and carbides. Ceram Int 30(7):1899-1904

Sutfin EL, Mccoy TP, Morrell HER, Hoeppner BB, Wolfson M (2013) Electronic cigarette use by college students. Drug Alcohol Depend 131(3):214-221

Takenaka S, Dornhöfer-Takenaka H, Muhle H (1986) Alveolar distribution of fly ash and of titanium dioxide after long-term inhalation by Wistar rats. J Aerosol Sci 17(3):361-364

Talih S, Belhas Z, Eissenberg T, Salman R, Karaoghlanian N, El Hellani A, Baalbaki R, Saliba N, Shihadeh A (2015) Effects of user puff topography, device voltage, and liquid nicotine concentration on electronic cigarette nicotine yield: measurements and model predictions. Nicotine Tobacco Res 17(2): $150-157$

U.S. Department of Health and Human Services (2016) Ecigarette use among youth and young adults. A report of the surgeon general. U.S. Department of Health and Human Services, Centers for Disease Control and Prevention, National Center for Chronic Disease Prevention and Health Promotion, Office on Smoking and Health, Atlanta

Vardavas CI, Filippidis FT, Agaku IT (2015) Determinants and prevalence of e-cigarette use throughout the European Union: a secondary analysis of 26566 youth and adults from 27 countries. Tob Control 24(5):442-448

Wilbur SB, States U, Syracuse RC (2000) Toxicological profile for chromium. U.S. Dept. of Health and Human Services, Public Health Service, Agency for Toxic Substances and Disease Registry, Atlanta

Williams M, Bozhilov K, Ghai S, Talbot P (2017) Elements including metals in the atomizer and aerosol of disposable electronic cigarettes and electronic hookahs. PLoS One 12(4):e0175430

Xu Y, Guo Y, Liu K, Liu Z, Wang X (2016) E-cigarette awareness, use, and harm perception among adults: a meta-analysis of observational studies. PLoS One 11(11):e0165938

Publisher's note Springer Nature remains neutral with regard to jurisdictional claims in published maps and institutional affiliations. 